\title{
Review of researches on smartphone applications for physical activity promotion in healthy adults
}

\author{
Haemi Jee* \\ Department of Sports and Health Care, Namseoul University, Cheonan, Korea
}

Physical activity is known as a preventative method for preventing lifestyle-related diseases. Smartphone applications for health and fitness intervention have released with rapid increase of innovative technology. Reviews of recent publications on mobile application have been conducted to observe feasibility and applicability for physical activity intervention. Bibliographic searches of PubMed and ScienceDirect were conducted with key terms, 'physical activity,' 'fitness,' 'smartphone,' and 'health' between the years 2014 and 2017 to obtain 5,087 publications. Out of 5,087 articles, five articles on sensor-based applications and five articles on user entry-based applications were obtained through the inclusion and exclusion processes. Accuracy of the physi- cal activity assessments were reported to be high in comparison to the conventional assessment tools. The overall subject rating on the app motivational ratings were positive with high correlation between physical activity and treats and cues. The adherence rates to the apps significantly dropped prior to 3 months. Publications that elucidate feasibility and accuracy of smartphone applications that motivates physical activity seem limited with adequately conducted study designs. Largescaled, control-compared, long-term randomized control trials should be conducted to elucidate the effects of the app interventions.

Keywords: Physical activity, Smartphone, Application, Activity promotion

\section{INTRODUCTION}

Noncommunicable diseases (NCD) such as cardiovascular and metabolic diseases have been major public health concerns in recent years (Schoeppe et al., 2016). NCDs were responsible for 38 out of 56 million or 38\% deaths in the year 2012 (World Health Organization, 2014). Numerous researches have reported of strong cause-and-effect relationship between NCD and various lifestyle modifications such as diet, physical activity, and sedentary behaviors. Improper diet, sedentary lifestyle, and inactivity are some of the major modifiable risk factors for prevention and management of NCDs. Unhealthy habits and behaviors such as unhealthy diet and sedentary lifestyle are difficult to change since such habits are acquired during childhood and carried into adulthood (Biddle et al., 2010; Craigie et al., 2011). Unhealthy habits acquired at young age are difficult to change and may require a long duration of modification efforts (Biddle et al., 2010; Craigie et al., 2011). Years of unhealthy lifestyle accumulate and aggra- vate various physiological problems to develop various NCDs. Once unhealthy lifestyle exacerbates potential factors for development of NCDs, reversing the negatively progressed physiological state is extremely difficult or even impossible. Numerous reports have stated that prevention is the optimal way of treating NCDs.

Smart devices such as smartphones and tablets have recently been emerging as integral part of people's life and assisting the users in various ways with innovative applications (apps). Health management is a large segment of the smart device usage. With a rapid increase in the smartphone distribution since 2007, there were about 6 billion mobile subscribers which accounted for $87 \%$ of the world's population in 2011 (Bender et al., 2013; Middelweerd et al., 2014; Schoeppe et al., 2016). Emergence of smartphone with powerful computing technology to support third-party application, Internet, wireless connectivity, and sensors such as accelerometer, gyroscope, and global positioning system (GPS) tracker, has opened up a new era for personal healthcare (Bender et al., 2013; Patrick et al., 2008). Along with a wide distribution of
${ }^{*}$ Corresponding author: Haemi Jee (i) http://orcid.org/0000-0002-9066-1472 Department of Sports and Health Care, Namseoul University, 91 Daehak-ro Seonghwan-eup Sebuk-gu, Cheonan 31020, Korea

Tel: +82-41-580-2993, Fax: +82-41-580-2912, E-mail: wlgpal9@gmail.com Received: November 30, 2016 / Accepted: January 1, 2017
This is an Open Access article distributed under the terms of the Creative Commons Attribution Non-Commercial License (http://creativecommons.org/licenses/by-nc/4.0/) which permits unrestricted non-commercial use, distribution, and reproduction in any medium, provided the original work is properly cited. 
smart devices and related innovative mobile applications, a vast number of low-cost or free healthcare applications have been released in recent years for continual and personalized monitoring of daily activities (Middelweerd et al., 2014). According to 148AppBiz (www.148apps.biz) and AppBrain (www.appbrain.com) statistics, 23,490 out of 875,683 active apps in iTunes and 17,756 out of 696,527 active apps in Google Play were categorized as health and fitness. In addition, companies such as Apple introduced HealthKit and ResearchKit which are open source frameworks for developers with visual consent flows, real-time dynamic active tasks, and surveys using a variety of customizable module to support development of health and medical apps worldwide (Baxter, 2016; Bot et al., 2016). Google Fit, which is an android fitness platform for health and fitness intervention by Google, lead to over 5 million downloads in 6 months since its first release in 2014 (Menaspà, 2015). Other global companies such as Microsoft and MSN also released similar platform to promote health and fitness related apps worldwide.

Clinical intervention has been the most effectively proven method for treating and preventing NCDs. However, clinical intervention has several limitations. Clinical intervention leads to financial, temporal, and spatial burden since it is usually carried out at an institution with medical personals specializing in the area of NCDs. In addition, the adherence rate of clinical interventions as a preventative measure has been reported to be low (Bert et al., 2014). Innovative technologies and wide distribution of handheld smartphones have provided several possible benefits in health and fitness management. Health and fitness applications may serve in several ways. Health and fitness related applications have the potential to improve health outcomes, medical cost, and regional health disparities (Silow-Carroll and Smith, 2013). However, despite the rapid release and distribution of health and fitness related applications, scientific feasibility studies on the applications are limited. One of the most important issues of health and fitness smartphone applications should be feasibility of information, which includes accuracy, validity, and reliability of data (Pandolfini et al., 2000). Application assessment and related application measures may provide credible information on the feasibility of the health and fitness care applications. Another important issue is the user adherence rate. Despite the feasibility and accuracy of an app, it would be considered ineffective if it does not promote continuous and active usage.

Therefore, this study reviewed publications that studied on the feasibility and adherence rate of smartphone based applications that are related to physical fitness intervention. Of particular in- terest, this review focused on applications or studies that are conducted to promote physical activity in healthy adults. Many of the smartphone based applications and related studies were conducted with different target groups, such as elderly, adolescents, and patients with various complications (Bot et al., 2016; Silow-Carroll and Smith, 2013). Moreover, most of the web applications on health with categories of fitness and physical activity, lifestyles and health, and nutrition targets the elderly (Bert et al., 2014). We focused on healthy adults since the application contents and the adherence rate may be different for prevention measures in healthy adults. Moreover, we have focused on applications that mainly targets healthy adults for general feasibility and efficacy. Furthermore, the applications were divided into sensor-based and entry-based applications to elucidate usability and efficacy.

\section{MATERIALS AND METHODS}

This review is based upon bibliographic searches of PubMed and ScienceDirect were conducted with relevant search terms, 'physical activity,' 'fitness,' 'smartphone,' and 'health' between the years 2014 and 2017. More specifically, terms, 'health,' or 'physical activity,' or 'fitness,' and 'smartphone,' or 'Iphone' or 'I-Phone,' or 'Android' were used as key terms in PubMed. Terms 'physical activity,' or 'health promotion,' or 'fitness,' and 'smartphone,' and 'app' or 'application,' were used as key terms in ScienceDirect. Articles were selected based on following inclusion criteria: (a) scientific articles that were searched with key terms mentioned above, (b) articles that analyzed smartphone application with primary outcome as physical activity, (c) intervention study with healthy adults, and (d) study designs with randomized control trial, experimental, longitudinal, cross-sectional study. In addition, articles were excluded based on following exclusion criteria: (a) articles or applications that mainly focus on physical or mental disease, (b) interventions of personal habits other than physical health and fitness, (c) case studies, (d) outcomes with physical activity as nonprimary outcome, and (e) studies on smartphone apps that required external devices.

In the initial search, 2,010 articles and 3,087 articles were obtained from PubMed and ScienceDirect, respectively. Articles from two databases were crossed checked for redundancy for the result of 5,051 articles. In order to select articles that mainly observed physical activity in healthy adults, following terms were used to filter out articles or apps related patients from the titles: most commonly appeared terms were patient, mental, drug, illness, incurable, endemic, chronic, infectious, epidemic, sunstroke, 
Table 1. Research studies on smartphone sensor-based physical activity intervention applications

\begin{tabular}{|c|c|c|c|c|c|c|c|c|}
\hline Study & Subjects & Sample size & Study design & Study duration & App name & App purpose & Primary outcome & Pros and cons \\
\hline $\begin{array}{l}\text { Harries et al., } 2016 \\
\text { (United Kingdom) }\end{array}$ & $\begin{array}{l}\text { Healthy males } \\
\text { (22-40 years) }\end{array}$ & 165 & $\begin{array}{l}\text { Randomized } \\
\text { controlled trial }\end{array}$ & 6 Weeks & bActive & Promotes PA & Steps per day & $\begin{array}{l}\text { Individual and group } \\
\text { compared feedback } \\
\text { showed } 60 \% \& 69 \% \\
\text { higher step-counts }\end{array}$ \\
\hline $\begin{array}{l}\text { Seto et al., } 2016 \\
\text { (China) }\end{array}$ & $\begin{array}{l}\text { College students } \\
\text { (mean age, } 24 \\
\text { years) }\end{array}$ & 12 Males & Cohort study & 2 Weeks & $\begin{array}{l}\text { CalFit Chi and } \\
\text { Dong (Phone } \\
\text { accelerometry, } \\
\text { GPS) }\end{array}$ & $\begin{array}{l}\text { Promotes PA } \\
\text { \& diet }\end{array}$ & $\begin{array}{l}\text { PA, food intake for } \\
\text { energy balance } \\
\text { assessment }\end{array}$ & $\begin{array}{l}\text { Voice-annotated } \\
\text { videos of meals }\end{array}$ \\
\hline $\begin{array}{l}\text { Vosa et al., } 2016 \\
\text { (The Netherland) }\end{array}$ & $\begin{array}{l}\text { Experience vs. no } \\
\text { experience } \\
\text { runners }\end{array}$ & $\begin{array}{l}28 \text { Experienced vs. } \\
\text { unexperienced } \\
\text { runners }\end{array}$ & $\begin{array}{l}\text { Randomized } \\
\text { controlled trial } \\
\text { with } 4 \text { focus } \\
\text { groups }\end{array}$ & $\begin{array}{l}12 \text { Months } \\
\text { ( } 2 \text { months } \\
\text { per group) }\end{array}$ & $\begin{array}{l}\text { Inspirun (GPS) } \\
\text { May add Bluetooth } \\
\text { HR monitor }\end{array}$ & $\begin{array}{l}\text { Supports } \\
\text { personalized } \\
\text { running } \\
\text { experience }\end{array}$ & $\begin{array}{l}\text { Application } \\
\text { usability by } \\
\text { survey }\end{array}$ & $\begin{array}{l}\text { Possible promotion } \\
\text { of PA \& participation }\end{array}$ \\
\hline $\begin{array}{l}\text { Furrer et al., } 2015 \\
\text { (Switzerland) }\end{array}$ & $\begin{array}{l}\text { Health adults } \\
\text { (mean age, } 27.4 \\
\text { years) }\end{array}$ & $\begin{array}{l}10 \text { Males } \\
12 \text { Males }\end{array}$ & $\begin{array}{l}\text { Cross-sectional } \\
\text { study }\end{array}$ & & Accelerometer & Gait analysis & $\begin{array}{l}\text { CoM displacement } \\
\& \text { step duration }\end{array}$ & $\begin{array}{l}\text { Comparison between } \\
\text { smartphone vs. motion } \\
\text { capture system, } \\
\text { displacement ICC } \\
\text { (0.71-0.80); time } \\
\text { ICC (0.79-0.86) }\end{array}$ \\
\hline $\begin{array}{l}\text { Nolan et al., } 2014 \\
\text { (Canada) }\end{array}$ & Healthy adults & 25 & $\begin{array}{l}\text { Randomized } \\
\text { controlled trial }\end{array}$ & & $\begin{array}{l}\text { Apple iPhone app, } \\
\text { accelerometer }\end{array}$ & $\begin{array}{r}\text { PA \& MET } \\
\text { analysis }\end{array}$ & $\begin{array}{l}\text { Walking, running } \\
\& E E \text { accuracy }\end{array}$ & $\begin{array}{l}\text { Bias of } 0.02 \&-0.03 \mathrm{~km} / \mathrm{hr} \text {, } \\
\text { Bias of } 0.35 \text { and }-0.43 \\
\text { METs for walking and } \\
\text { running ( } 99 \% \text { accuracy } \\
\text { compared with treadmill) }\end{array}$ \\
\hline
\end{tabular}

App, application; CoM, vertical center of mass; METs, metabolic equivalents; PA, physical activity; GPS, global positioning system; HR, heart rate; EE, energy expenditure; ICC, intraclass correlation coefficient.

anemia, tonsils, hemorrhoids, asthma, mumps, chickenpox, smallpox, measles, polio, rheumatism, arthritis, duodenalulcer, appendicitis, ulcers, gastritis, renal calculus, kidney, failure, leukemia, tuberculosis, pneumonia, bronchitis, heart attack, heart failure, disease, cancer, hepatitis, stroke, hypotension, hypertension, diabetes, disability, injury, injuries, pandemic, children, secure, security, smart watch, smartwatch, ethical, vaccine, nursing, nurse, surgery, cardiovascular, corticospinal, alcohol, child, sick, fall detection, medical, phenotyping, neoplasia, young adult, adolescent, cardiology, trauma, psychological, fibromyalgia, psychology, disaster, blind, shopping, brain, dental, sexual, e-learning, smart, home, car, medication, medicine, pill, pregnant, economy, vehicle, blood, business, safety, human immunodeficiency virus, infect, teledermatology, electrocardiograph, microfluidic, vehicular, pain, sleep, world war, smart city, disorder, pay, ecosystem, smoke, smoking, trachoma, TV, driver, and epileptic. Through the term exclusion process, 1,834 articles were excluded, remaining 3,217 articles.

Second filtering process with the title of the articles categorized the articles into three groups, (a) unrelated topics (2,980 articles), (b) ambiguous topics and/or subjects (153 articles), and (c) suitable articles ( 84 articles). Abstracts of the articles with ambiguous topics and/or subjects and suitable articles were reviewed for correlation with the topic of this review. Similar categorization pro- cess was conducted to obtain unrelated topics (195 articles), ambiguous topics and/or subjects (13 articles), and suitable articles (43 articles). The articles with unrelated topics and 14 review articles were excluded to obtain 42 articles. Review articles were crosscheck for redundancy and providing directional information of this review paper.

Finally, abstracts or full texts of the remaining articles were reviewed to obtain 10 eligible research articles that are related to the topic of this study (Table 1). Thirty-two articles were excluded for contents irrelevant to the topic of this article, articles based on applications that required external devices, or articles that are case studies. Of the 10 included studies, five articles analyzed sensor-based applications and five articles analyzed data entry-based applications. The articles were sorted and arranged in Tables 1 and 2. The tables contain information such as article or study title, targeted subjects, sample size, study design, study duration, app name, app purpose, primary outcome, and summary on critical points of the study.

\section{RESULTS}

This review analyzed two of the major search engines on scientific articles, PubMed and ScienceDirect to exclude 5,088 articles 
Table 2. Research studies on smartphone entry-type physical activity intervention applications

\begin{tabular}{|c|c|c|c|c|c|c|c|c|}
\hline Study title & Subjects & Sample size & Study design & Study duration & App name & App purpose & Primary outcomes & Results \\
\hline $\begin{array}{l}\text { Klein et al., } 2014 \\
\text { (Dutch) }\end{array}$ & $\begin{array}{l}\text { Healthy adults } \\
\text { (21-64 years) }\end{array}$ & $\begin{array}{l}20 \text { Males, } 20 \\
\text { females }\end{array}$ & $\begin{array}{l}\text { Anonymous } \\
\text { online/email } \\
\text { survey-42 } \\
\text { questions }\end{array}$ & $\begin{array}{l}15 \text { Minutes } \\
\text { for survey }\end{array}$ & & $\begin{array}{l}\text { Supports } \\
\text { behavioral } \\
\text { change }\end{array}$ & Adherence to PA & $\begin{array}{l}\text { PA cue \& threat ( } r=-0.50) \text {, } \\
\text { PA cue \& self-efficacy } \\
\text { ( } r=-0.51) \\
\text { Sign correlation between } \\
\text { days of PA and threat, } \\
\text { attitude, self-efficacy, } \\
\text { mood \& cues }\end{array}$ \\
\hline $\begin{array}{l}\text { Alnasser et al., } 2016 \\
\text { (Saudi Arabia) }\end{array}$ & $\begin{array}{l}2 \text { Healthcare } \\
\text { provider, } 3 \\
\text { nutritionist, } 10 \\
\text { obese females, } \\
18 \text { years }\end{array}$ & 8 & Survey & 5-7 Days & Twazon & $\begin{array}{l}\text { PA \& weight } \\
\text { reduction, } \\
\text { food, } \\
\text { behavior } \\
\text { change }\end{array}$ & $\begin{array}{l}\text { App raised } \\
\text { awareness, } \\
\text { encouraged } \\
\text { commitment, } \\
\text { self-monitoring }\end{array}$ & $\begin{array}{l}\text { Provides PA \& lifestyle } \\
\text { information }\end{array}$ \\
\hline $\begin{array}{l}\text { Shin et al., } 2017 \\
\text { (Korea) }\end{array}$ & $\begin{array}{l}\text { Male students, } \\
\text { BMI> 27, } \\
19-45 \text { years }\end{array}$ & $\begin{array}{l}105 \text { traditional, } \\
\text { app vs. } \\
\text { app+incentive } \\
\text { groups }\end{array}$ & $\begin{array}{l}\text { Pilot } \\
\text { randomized } \\
\text { trial }\end{array}$ & 12 Weeks & Smartcare & $\begin{array}{l}\text { PA as weight } \\
\text { control }\end{array}$ & $\begin{array}{l}\text { Weight, lab tests, } \\
\text { nutrition, PA: } \\
\text { financial incentive } \\
\text { as significant factor }\end{array}$ & $\begin{array}{r}\text { Fitmeter accelerometer } \\
\text { used for PA measures }\end{array}$ \\
\hline $\begin{array}{l}\text { Morrison et al., } 2014 \\
\text { (United Kingdom) }\end{array}$ & $\begin{array}{l}\text { Adults, } 18-52 \\
\text { years }\end{array}$ & $\begin{array}{l}6 \text { Males, } 7 \\
\text { females }\end{array}$ & $\begin{array}{l}\text { Randomized } \\
\text { control trial }\end{array}$ & 4 Weeks & POWeR & $\begin{array}{l}\text { Weight control } \\
\text { via PA }\end{array}$ & $\begin{array}{l}\text { Self-reported goal } \\
\text { effort \& motivation, } \\
\text { efficacy, and PA } \\
\text { achievement }\end{array}$ & Significant PA awareness \\
\hline $\begin{array}{l}\text { Duncan et al., } 2014 \\
\text { (Australia) }\end{array}$ & $\begin{array}{l}\text { Male adults, } \\
35-54 \text { years }\end{array}$ & $\begin{array}{c}301 \text { (205 SA, } 96 \\
\text { print group) }\end{array}$ & $\begin{array}{l}\text { Randomized } \\
\text { controlled trial }\end{array}$ & 9-Months & ManUp & $\begin{array}{l}\text { PA \& dietary } \\
\text { behavior }\end{array}$ & $\begin{array}{l}\text { Dropout users per } \\
\text { week (baseline, 3-, } \\
\text { 9-month survey) } \\
\text { Rapid decline in app } \\
\text { view at 3,9 months }\end{array}$ & $\begin{array}{l}\text { Used both web and smart- } \\
\text { phone, improvements in } \\
\text { PA \& diet, no between } \\
\text { difference }\end{array}$ \\
\hline
\end{tabular}

App, application; PA, physical activity; BMI, body mass index; SA, smartphone app.

that are unrelated to the topic of this review to obtain 10 articles between the years 2014 and 2017. Most of the excluded articles were on applications related to various clinical complications including mental and physiological diseases. In addition, many of the articles were related to application assessment or technical aspects of application development. In addition, since this study focused on studies that dealt with healthy adults between the age of 18 and 70, many of the studies that observed younger or older groups were also excluded. Selected articles were divided by data assessment methods of smartphone built-in sensor based data collection method (Table 1) and user entered data collection method (Table 2) (Alnasser et al., 2016; Duncan et al., 2014; Furrer et al., 2015; Harries et al., 2016; Klein et al., 2014; Morrison et al., 2014; Nolan et al., 2014; Seto et al., 2016; Shin et al., 2017; Vosa et al., 2016). Published studies included both qualitative and qualitative studies: one focus group study, four randomized control trials, one cohort study, one cross-sectional study, and two surveys.

\section{Researches on smartphone sensor utilizing applications}

Most of the applications utilized either a GPS tracker or accelerometer sensor or both smartphone built-in sensors. Among the selected five studies for review of the smartphone sensor-based physical activity intervention applications, the study performed by Harries et al. (2016) utilized the most number of young male subjects to observe the feasibility of a physical activity promotion application for the duration of 6 weeks. This randomized controlled trial assessed 165 male participants between the ages 18 to 40 by dividing subjects into three groups, no feedback, individual feedback, and individual and social feedback groups, to compare differences in step counts. Continuous step-count assessment smarphone apps significantly increased physical activity by $60 \%$ and $69 \%$ in the individual feedback and individual, and social feedback groups in comparison to the no feedback group, respectively, without significant increase between the individual feedback, individual, and social feedback groups.

Second study observed 12 college students ( $67 \%$ females) to assess food intake, emotional assessment, and physical activity for the duration of 2 weeks (Seto et al., 2016). Voice-annotated videos of meals were used to determine the portion size and type of food, and accelerometer data was used to tract movements. Primary purpose of the app was to promote healthier lifestyle through monitoring eating behavior along with the emotional state. Interesting outcome was that physical activity of the subjects occurred around each meal and had the tendency to affect subjects' eating behavior.

Third study observed 28 runners with and without previous experiences of running (Sejdić et al., 2015). Surveys were conducted 
after each of four focus groups analyzed the runner support app, Inspirun, for satisfaction and usability for the duration of about 2 months. Four focus groups were used so the app could be improved for its content after each survey. First group was composed of social competitive runners, second group was composed of individual fitness runners, third group was composed of individual competitive runners, and fourth group was composed of social runners. Surveys were conducted after the app interventions. Results of the study showed that each group had different drives for running - competition, health, performance, or running together. The study pointed out the importance of personalized approach combination of a personalized coaching approach with the automatic adjustment for training scheme for promotion of physical activity.

Furrer et al. (2015) conducted a cross-sectional study on the quantification of level walking with 22 young healthy adults with mean age of 27.4 years. The study analyzed vertical center of mass $(\mathrm{CoM})$ and step duration by comparing with conventional assessment tool of motion capture system. The results showed excellent reliability and strong correlation for $\mathrm{CoM}$ displacement (intraclass correlation coefficient [ICC], 0.71-0.80) and step duration (ICC, 0.79-0.86) which suggested reliability of user-friendly smartphone app for gait pattern detection in healthy young adults.

A study on smartphone application with a built-in accelerometer for accuracy in walking and running speed estimation was included in this review (Nolan et al., 2014). Twenty-five healthy adults performed treadmill walking and running with smartphones on them to obtain $99 \%$ accuracy with a bias of $0.02 \mathrm{~km} /$ $\mathrm{hr}$ for walking and $-0.03 \mathrm{~km} / \mathrm{hr}$ for running. In addition, energy expenditure prediction biases were 0.35 metabolic equivalents (METs) for walking and -0.43 METs for running.

\section{Researches on smartphone user entry-type applications}

Five studies which analyzed applications that mainly used user entered data for activity analysis were selected for the study.

Klein et al. (2014) observed smartphone based app which obtained and monitored physical activity and food intake behavior through a web-based calendar and graphical questions. Physical activity duration in minutes, dates, and types (walking, cycling, sports) were registered on the calendar by the users. In addition, the degree of adherence was calculated by comparing registered duration with designated health goals. Positive correlations were found between physical activity and threat $(r=0.65, P<0.01)$, and cues $(r=0.60, P<0.05)$, and stage of change of physical activity and body mass index (BMI) $(r=-0.49, P<0.05)$. In addition, number of days of fruit and vegetables intake were highly cor- related with attitude $(r=0.65, P<0.01)$, self-efficacy $(r=0.67$, $P<0.01)$, and positive $\operatorname{mood}(r=0.51, P<0.05)$ with consistent correlation between BMI and the stage of behavior change and physical activity and healthy food intake.

A study by Alnasser et al. (2016) was conducted with eight young female subjects and the applicability of an app that focuses on physical activity and weight reduction support. The app was developed for Arabic population with graphic design for both iPhone operating system and Android platforms. The app recommended minimum of 30 minutes of physical activity 3 times a week and at least 10,000 steps. Energy expenditure was calculated using the compendium of physical activity and corresponding metabolic equivalents. A survey with open-end questions was conducted after 5 to 7 days of evaluation by the users and the users provided feedback indicated strong awareness for physical activity and food consumption.

Shin et al. (2017) conducted a randomized control trial with 105 male students between the ages 19 to 45 years to analyze self-reported goal effect, motivation, efficacy, physical activity achievement on weight control, and physical activity for the duration of 4 weeks. The subjects that were divided into the traditional education, app intervention, and app intervention with financial incentive groups showed average weight loss of $0.4,1.1$, and 3.1 $\mathrm{kg}$, respectively, with significantly greater weight loss and achievement of the final weight loss goal with odd ratio of 7.27 in the third group. Physical activity levels were also significantly higher in the app intervention with financial incentive group.

Morrison et al. (2014) conducted an intervention study with an Android mobile phone app that track personal goal to enhance users' awareness of and motivation with 13 subjects for a duration of 4 weeks. The app provides daily questionnaires to the users to obtain the self-report measures of goal engagement. Based on the Health Action Process Approach, the study assessed goal pursuit, coping self-efficacy, action control (awareness effort), and achievement of goals through the app (Kang et al., 2009; Sniehotta et al., 2005). The study suggested that the app-based tool had the potential to improve individuals' motivation and awareness on the subjects' eating and physical activity goals.

Duncan et al. (2014) conducted a randomized controlled trial study with 301 middle-aged males between the ages of 35 to 54 years for the duration of 9 months. Mobile app-and printed-based interventions were compared between two randomly divided groups for the adherence to physical activity and dietary behavior guidelines. Both mobile app- and print-based interventions showed improvements in physical activity and dietary behavior 
without significant differences between two intervention modalities. However, rapid declines in weekly views of the app- and print-based interventions were shown at 3 and 9 months.

\section{DISCUSSION}

In recent years, there has been a rapid rise in innovative technological advancements designed to support health and fitness behavioral change. Innovative technological advancements include computer and Internet based platforms, social networks, and handheld mobile devices (Morrison et al., 2014). Smartphones with their apparent ubiquity and handiness lead to widespread penetration into people's daily lives, and infinite application possibilities for a smartphone based health and fitness management market (Klasnja and Pratt, 2012; Miller, 2012). Release of open source frameworks for developers by companies such as Apple, Google, Microsoft, and HealthVault and release of over 50 thousand active apps for health and fitness along with related innovative technology related to health and fitness in recent years allow understanding of the trend and widespread interest of smartphone-based health and fitness applications (Baxter, 2016; Bot et al., 2016). In light of massive release of health and fitness related smartphone applications, the applicability and feasibility assessment of the apps on physical fitness in general population seem necessary for situational analysis and futuristic direction. The current review assessed 10 articles that observed smartphone based applications for physical activity tracking through assessment out of 5,000 articles release between the years 2014 to 2017.

A study observed in this review analyzed the physical activity monitoring accuracy of an application that utilized smartphone built-in sensor reported of excellent accuracy (99\%) (Nolan et al., 2014). However, there are mix results on the accuracy of smartphone applications for physical activity monitoring. A comparative study between pedometers/accelerometers, wearable devices, and smartphone applications reported of $-0.3 \%$ to $1.0 \%,-22.7 \%$ to $1.5 \%$, and $-6.7 \%$ to $6.2 \%$ differences in mean steps during 500 and 1,500 step trials (Case et al., 2015). Although the accuracy was higher than the wearable devices, smartphone apps showed comparatively lesser accuracy than the previous study mentioned. Such differences may be due to the environment of the study conducted. Previous study with excellent accuracy was conducted in a controlled environment with a treadmill, whereas the step count comparison study was conducted in a open field environment (Case et al., 2015; Nolan et al., 2014).

Recent review on top-ranked physical activity apps emphasized behavior change techniques through education and motivation (Conroy et al., 2014). This may be the reason for significant amount survey studies to bridge the intention-behavioral gap in recent studies, since the studies that analyzed well-established technique to bridge in intention-behavioral gap was rarely conducted (Bélanger-Gravel et al., 2013). In this study, 3 out of 4 studies that assessed the user entry-type smartphone apps and 1 out of 5 studies that assessed the sensor-based smartphone apps utilized surveys with major primary outcomes of user intentions including self-reported goal effort, motivation, awareness, efficacy, achievement, mood, and cue (Alnasser et al., 2016; Klein et al., 2014; Morrison et al., 2014).

Noticeable decline in adherence to the app-based intervention was shown during long-term intervention studies (Duncan et al., 2014; Shin et al., 2017). In addition, previous study conducted for 3 months reported that 3 months was not sufficient for behavioral change to promote physical activity as a habit (Recio-Rodriguez et al., 2013; Recio-Rodríguez et al., 2014). Such user adherence declining pattern was shown in previous studies (Brindal et al., 2012; Glasgow et al., 2011). Interestingly, the adherence rate to an app-based intervention was not significantly different in comparison to the conventional intervention method (Duncan et al., 2014). Moreover, the effectiveness of intervention was noticeably increased when financial incentive was provided with an intervention (Shin et al., 2017).

Major focus of recently released smartphone apps was to motivate behavioral changes (Conroy et al., 2014). The most common behavioral change techniques suggested by the apps which composed about $44 \%$ of all techniques were providing or demonstrating 'instruction on performance behavior,' 'behavior,' 'feedback on performance,' 'goal-setting for behavior,' 'planned social support or change, ' 'information on others' approval,' and 'goal-setting for outcome,' 'review of behavioral goals,' 'social comparison,' 'structured graded tasks,' 'review of outcome goals.' 'time and location of behavior performance,' 'self-monitoring of behavior,' and 'self-monitoring of behavioral outcomes' (Conroy et al., 2014). Previous results also emphasized the importance of motivational techniques to promote physical activity along with tailored feedback toward personally set goals (Conroy et al., 2014; Coughlin et al., 2016).

In that sense, the user entry-type smartphone apps did not show strong motivational results. In some cases, the studies allowed usage of external devices as accelerometer or pedometer to count the steps taken by the subjects. Some of the studies pointed out on the cumbersomeness of carrying external devices to record 
the amount of physical activity performed (Conroy et al., 2014). One of the major advantages of smartphone intervention has been reported to be automated feedback displays and easily automated motivational messages without expensive face-to-face support, motivation or instruction to easily deliver affordable promotion even in large populations (Harries et al., 2016; Kang et al., 2009; Winett et al., 2007).

Overall, studies reviewed consistently reported that mobile app interventions motivated behavioral changes through awareness and threat. Mixed results were shown on the effectiveness of increased physical activity and other health related behavior, especially for an extended period of intervention. Although mobile apps have the potential to increase physical activity level, only about $20 \%$ of the users consistently adhere to the app and 3\% become long-term users (Direito et al., 2015; Helander et al., 2014). A study that reviewed a total of 26 articles also reported of mixed results of the effectiveness of smartphone apps. It reported that four studies reported physical activity increase (12-42 subjects, 800 to 1,104 steps/day, 2 weeks to 6 months), and one case-control study reported physical activity maintenance (200 participants; > 10,000 steps/day) over 3 months (Bort-Roig et al., 2014).

Apps should have features to repeatedly motivate and attractive users such as user-friendly design, features, and usability (Schoeppe et al., 2016). In addition, in order for an app to be an effective physical activity intervention tool, it should incorporate behavior change techniques. For example, immerse type of apps with lesion components such as games and virtual reality with user engagement have been reported to be have greater potential to increase user adherence (Helander et al., 2014).

Most of the smartphone apps are available from either android, IPhone or iTunes store (Direito et al., 2014; Direito et al., 2015). Conroy et al. (2014) reported that of the 200 screened available health and fitness apps with 167 apps (84\%) involved in physical activity. Despite a large number of applications, there are limited number of applications that performed feasibility assessments with reliable assessment procedure and subjects. For example, $60 \%$ of the reviewed studies conducted their studies with less than 25 subjects and most of the studies were conducted without controls. Moreover, a study with 28 subjects were conducted with 4 different focus groups which resulted in average of 6 subjects per group (Vosa et al., 2016). Overall, there were a limited number of studies that utillized a large group of healthy adults as subjects and controls for the accuracy assessment of smartphone sensor based applications for physical activity promotion. However, there are signs of long-term, large-group studies designed for the upcoming years.

For example, a randomized double-blinded, multicenter, clinical trial study was designed for the duration of 3 months with 1,215 subjects less than the age of 70 years and an app with monitors physical activity and dietary management was designed to be conducted in the future (Recio-Rodríguez et al., 2014). This study focuses on the possibility of behavioral change through self-reported information on physical activity and food consumption for the vascular health benefits. The study composed of six groups of subjects from six different locations in Spain and will be proceed with physical activity monitoring with built-in accelerometer, 7-day physical activity recall, and ActiGraph. This study is based on a proceeding study which reported of a significant association between less than recommended level of physical activity or prolonged sedentarism with greater aging of the vascular system (Recio-Rodriguez et al., 2013; Recio-Rodríguez et al., 2014). Such large group studies with group comparisons may be a valid way to evaluate current status on smartphone applications and provide futuristic guidelines.

Smartphone applications may serve to provide self-monitoring purpose or client or patient counseling purpose. Self-monitoring apps may provide necessary information that a person need to motivate oneself and to obtain proper amount physical activity and related health promotional habits. Client-counseling applications may assist health care professionals to closely guide and educate clients for promotion of specific fitness and dietary modifications with client awareness on lifelong habits (Silow-Carroll and Smith, 2013).

With respect to limitations of the current review, some published studies may have been overlooked if they were not included in PubMed or ScienceDirect or the publications did not match the key terms. Publications that reviewed smartphone applications for physical activity pointed out lack of credible feasibility studies to fully elucidate current status of the smartphone applications and their futuristic directions (Case et al., 2015). However, currently reported status on studies on smartphone applications may underestimate the real number of works and researches related to this topic. It is difficult to make a confirming statement on the innovative technological developments that are rapidly evolving even in this right moment. However, studies with randomized controlled trial research designs, larger sample sizes, control group, and longer study periods should be conducted to explore the physical activity measurement and intervention capabilities of the smartphone based applications to prepare for the future (Glynn et al., 2013; Knight et al., 2015). 


\section{CONFLICT OF INTEREST}

No potential conflict of interest relevant to this article was reported.

\section{ACKNOWLEDGMENTS}

Funding for this paper was provided by Namseoul University year 2016. The author would like to express the deepest gratitude to graduate students, Seung Ryul Kim and Sumin Ahn of Embedded Lab of Inha University for the support they have given for reviewing publications related to this study.

\section{REFERENCES}

Alnasser A, Sathiaseelan A, Al-Khalifa A, Marais D. Development of 'Twazon': An Arabic App for Weight Loss. JMIR Res Protoc 2016;5:e76. Baxter C: Symptom and measurement tracker. In: Beginning CareKit development: develop CareKit applications using swift. Berkeley (CA): Apress; 2016. p. 75-99.

Bélanger-Gravel A, Godin G, Amireault S. A meta-analytic review of the effect of implementation intentions on physical activity. Health Psychol Rev 2013;7:23-54

Bender JL, Yue RY, To MJ, Deacken L, Jadad AR. A lot of action, but not in the right direction: systematic review and content analysis of smartphone applications for the prevention, detection, and management of cancer. J Med Internet Res 2013;15:e287.

Bert F, Giacometti M, Gualano MR, Siliquini R. Smartphones and health promotion: a review of the evidence. J Med Syst 2014;38:9995.

Biddle SJ, Pearson N, Ross GM, Braithwaite R. Tracking of sedentary behaviours of young people: a systematic review. Prev Med 2010;51:345351.

Bort-Roig J, Gilson ND, Puig-Ribera A, Contreras RS, Trost SG. Measuring and influencing physical activity with smartphone technology: a systematic review. Sports Med 2014;44:671-686.

Bot BM, Suver C, Neto EC, Kellen M, Klein A, Bare C, Doerr M, Pratap A, Wilbanks J, Dorsey ER, Friend SH, Trister AD. The mPower study, Parkinson disease mobile data collected using ResearchKit. Sci Data 2016;3:160011

Brindal E, Freyne J, Saunders I, Berkovsky S, Smith G, Noakes M. Features predicting weight loss in overweight or obese participants in a web-based intervention: randomized trial. J Med Internet Res 2012; 14:e173.

Case MA, Burwick HA, Volpp KG, Patel MS. Accuracy of smartphone applications and wearable devices for tracking physical activity data.
JAMA 2015;313:625-626.

Conroy DE, Yang CH, Maher JP. Behavior change techniques in topranked mobile apps for physical activity. Am J Prev Med 2014;46:649652.

Coughlin SS, Whitehead M, Sheats JQ, Mastromonico J, Smith S. A Review of Smartphone Applications for Promoting Physical Activity. Jacobs J Community Med 2016;2:021.

Craigie AM, Lake AA, Kelly SA, Adamson AJ, Mathers JC. Tracking of obesity-related behaviours from childhood to adulthood: a systematic review. Maturitas 2011;70:266-284.

Direito A, Dale LP, Shields E, Dobson R, Whittaker R, Maddison R. Do physical activity and dietary smartphone applications incorporate evidence-based behaviour change techniques? BMC Public Health 2014; 14:646.

Direito A, Jiang Y, Whittaker R, Maddison R. Apps for IMproving FITness and increasing physical activity among young people: the AIMFIT pragmatic randomized controlled trial. J Med Internet Res 2015; 17:e210.

Duncan M, Vandelanotte C, Kolt GS, Rosenkranz RR, Caperchione CM, George ES, Ding H, Hooker C, Karunanithi M, Maeder AJ, Noakes M, Tague R, Taylor P, Viljoen P, Mummery WK. Effectiveness of a weband mobile phone-based intervention to promote physical activity and healthy eating in middle-aged males: randomized controlled trial of the ManUp study. J Med Internet Res 2014;16:e136.

Furrer M, Bichsel L, Niederer M, Baur H, Schmid S. Validation of a smartphone-based measurement tool for the quantification of level walking. Gait Posture 2015;42:289-294.

Glasgow RE, Christiansen SM, Kurz D, King DK, Woolley T, Faber AJ, Estabrooks PA, Strycker L, Toobert D, Dickman J. Engagement in a diabetes self-management website: usage patterns and generalizability of program use. J Med Internet Res 2011;13:e9.

Glynn LG, Hayes PS, Casey M, Glynn F, Alvarez-Iglesias A, Newell J, Ólaighin G, Heaney D, Murphy AW. SMART MOVE - a smartphone-based intervention to promote physical activity in primary care: study protocol for a randomized controlled trial. Trials 2013;14:157.

Harries T, Eslambolchilar P, Rettie R, Stride C, Walton S, van Woerden HC. Effectiveness of a smartphone app in increasing physical activity amongst male adults: a randomised controlled trial. BMC Public Health 2016;16:925.

Helander E, Kaipainen K, Korhonen I, Wansink B. Factors related to sustained use of a free mobile app for dietary self-monitoring with photography and peer feedback: retrospective cohort study. J Med Internet Res 2014;16:e109.

Kang M, Marshall SJ, Barreira TV, Lee JO. Effect of pedometer-based physical activity interventions: a meta-analysis. Res Q Exerc Sport 


\section{9;80:648-655.}

Klasnja P, Pratt W. Healthcare in the pocket: mapping the space of mobile-phone health interventions. J Biomed Inform 2012;45:184-198.

Klein M, Mogles N, van Wissen A. Intelligent mobile support for therapy adherence and behavior change. J Biomed Inform 2014;51:137-151.

Knight E, Stuckey MI, Prapavessis H, Petrella RJ. Public health guidelines for physical activity: is there an app for that? A review of android and apple app stores. JMIR Mhealth Uhealth 2015;3:e43.

Menaspà P. Effortless activity tracking with Google Fit. Br J Sports Med 2015;49:1598.

Middelweerd A, Mollee JS, van der Wal CN, Brug J, Te Velde SJ. Apps to promote physical activity among adults: a review and content analysis. Int J Behav Nutr Phys Act 2014;11:97.

Miller G. The Smartphone Psychology Manifesto. Perspect Psychol Sci 2012;7:221-237.

Morrison LG, Hargood C, Lin SX, Dennison L, Joseph J, Hughes S, Michaelides DT, Johnston D, Johnston M, Michie S, Little P, Smith PW, Weal MJ, Yardley L. Understanding usage of a hybrid website and smartphone app for weight management: a mixed-methods study. J Med Internet Res 2014;16:e201.

Nolan M, Mitchell JR, Doyle-Baker PK. Validity of the Apple iPhone® / iPod Touch ${ }^{\circledR}$ as an accelerometer-based physical activity monitor: a proof-of-concept study. J Phys Act Health 2014;11:759-769.

Pandolfini C, Impicciatore P, Bonati M. Parents on the web: risks for quality management of cough in children. Pediatrics 2000;105:e1.

Patrick K, Griswold WG, Raab F, Intille SS. Health and the mobile phone. Am J Prev Med 2008;35:177-181.

Recio-Rodriguez JI, Gomez-Marcos MA, Patino-Alonso MC, Romaguera-Bosch M, Grandes G, Menendez-Suarez M, Lema-Bartolome J, Gonzalez-Viejo N, Agudo-Conde C, Garcia-Ortiz L; EVIDENT Group. Association of television viewing time with central hemodynamic parameters and the radial augmentation index in adults. Am J Hypertens 2013;26:488-494.

Recio-Rodríguez JI, Martín-Cantera C, González-Viejo N, Gómez-Arranz A, Arietaleanizbeascoa MS, Schmolling-Guinovart $Y$, Maderuelo-Fernandez JA, Pérez-Arechaederra D, Rodriguez-Sanchez E, Gómez-Marcos MA, García-Ortiz L; EVIDENT Group. Effectiveness of a smartphone application for improving healthy lifestyles, a randomized clinical trial (EVIDENT II): study protocol. BMC Public Health 2014;14:254.

Schoeppe S, Alley S, Van Lippevelde W, Bray NA, Williams SL, Duncan MJ, Vandelanotte C. Efficacy of interventions that use apps to improve diet, physical activity and sedentary behaviour: a systematic review. Int J Behav Nutr Phys Act 2016;13:127.

Sejdić E, Millecamps A, Teoli J, Rothfuss MA, Franconi NG, Perera S, Jones AK, Brach JS, Mickle MH. Assessing interactions among multiple physiological systems during walking outside a laboratory: an Android based gait monitor. Comput Methods Programs Biomed 2015;122:450-461.

Seto E, Hua J, Wu L, Shia V, Eom S, Wang M, Li Y. Models of individual dietary behavior based on smartphone data: the influence of routine, physical activity, emotion, and food environment. PLoS One 2016;11: e0153085.

Shin DW, Yun JM, Shin JH, Kwon H, Min HY, Joh HK, Chung WJ, Park $\mathrm{JH}$, Jung KT, Cho B. Enhancing physical activity and reducing obesity through smartcare and financial incentives: a pilot randomized trial. Obesity (Silver Spring) 2017;25:302-310.

Silow-Carroll S, Smith B. Clinical management apps: creating partnerships between providers and patients. Issue Brief (Commonw Fund) 2013;30:1-10.

Sniehotta FF, Scholz U, Schwarzer R. Bridging the intention-behaviour gap: planning, self-efficacy, and action control in the adoption and maintenance of physical exercise. Psychol Health 2005;20:143-160.

Vosa S, Janssena M, Goudsmita J, Lauwerijssenc C, Brombacherb A. From problem to solution: Developing a personalized smartphone application for recreational runners following a three-step design approach. Proced Eng 2016;147:799-805.

Winett RA, Anderson ES, Wojcik JR, Winett SG, Bowden T. Guide to health: nutrition and physical activity outcomes of a group-randomized trial of an Internet-based intervention in churches. Ann Behav Med 2007;33:251-261.

World Health Organization. Global status report on noncommunicable diseases 2014. Geneva: World Health Organization; 2014. 